\title{
Feminidad y uso de la fuerza: la fabricación de una heroína a partir de la serie de televisión Nikita
}

\author{
SABRINA CALANDRÓN
}

El objetivo central de este artículo es mostrar las variadas y complejas relaciones entre el uso de la fuerza física y la feminidad. Se analizan las concepciones culturales sobre las mujeres dedicadas al ejercicio sistemático de la violencia corporal y letal en historias de ficción televisivas de acción. A partir del caso paradigmático de la serie estadounidense Nikita, realizada en 2010 y transmitida en varios países de Latinoamérica, ofrecemos una mirada crítica de las visiones clásicas que explican la fuerza física como marca exclusiva de masculinidad. La musculación física, la destreza aeróbica, la activación sexual y la autonomía de las mujeres respecto de los protagonistas varones en historias ficticias de acción colaboran a construir una narrativa de expresión de la feminidad contemporánea.

PALABRAS CLAVE: feminidad, fuerza física, corporalidad, heroínas, series de televisión

Femininity and Use of Physical Force: Nikita, How to Make a Heroine in TV series

The central subject of this article is to show the varied and complex relationships between the use of physical force and femininity. In this regard, we analyze the cultural conceptions of women dedicated to the systematic exercise of corporal and lethal violence in action TV series. Based on the case of the paradigmatic TV series Nikita, produced and aired in 2010, we offer a critical review to the classic visions that explain physical force as a masculine exclusive brand. Physical fitness, aerobic ability, sexual activation and the empowerment of women in respect of male protagonists in action fictions contributes to build a narrative expression of contemporary femininity. 


\section{Introducción}

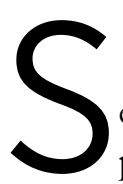

e escucha música de piano. Nikita toma un té en un lugar con luces bajas, pulcro y ordenado. La iluminación no lo hace oscuro sino exclusivo. Trevor, en un traje impecable, le lanza un halago: "siempre fuiste una de mis clientes favoritas". La escena juega a confundirnos al sugerir que la mujer está comprando joyas o prendas de costura excepcional. Trevor continúa su alabanza y le deja claro que puede elegir el modelo que desee, pues él tiene varios accesorios que pueden integrarse. El plano se abre y Nikita camina alrededor de una mesa, acaricia un fusil automático de asalto desde la culata hasta la boca del cañón: "ése es bonito", dice. "Ése es mío", aclara Trevor. Camina unos pasos más y con un movimiento rápido y preciso destapa una ametralladora que está sobre un soporte: "un encanto". Le dice que quiere esa "Lokken 2-12" — sabe con exactitud cuál es el modelo, sin preguntarlo- y un lente térmico. Nikita se inclina hacia adelante y mira de cerca la imponente arma que está casi en exhibición. "Imagino que es el mismo precio", balbucea Nikita mientras la contempla detalle a detalle. Trevor, sereno, indica que el precio acaba de aumentar y le apunta con el fusil de asalto táctico. Con esto da a entender que la muerte de Nikita está muy bien cotizada. Intenta disparar, pero - sorpresa - no tiene balas. Ahora los espectadores sabemos que al pasar cerca del fusil Nikita le quitó el cargador. La mujer toma la ametralladora y apunta hacia el cuerpo del vendedor - ahora - traicionero. La ametralladora está montada para tiro. Con una voz dulce, ella le propone un nuevo trato: "me quedo con el arma, tú sigues respirando y no le dices a nadie que estuve aquí".

Ésta es la escena inicial de uno de los capítulos de la serie Nikita (Silverstein, Egilsson y Fink, 2010-2013), televisada durante 2010 en Estados Unidos, con la actriz Maggie Q como protagonista. Nikita Mears es una mujer de unos 30 años de edad con un pasado criminal que la llevó a la condena a muerte. La División Especial simuló su deceso, pero la absorbió para entrenarla en defensa personal, uso de armas y espionaje. Nikita se convirtió en una de las mejores agentes de la División, 
pero, según su propio relato, cometió un error: se enamoró de un hombre perteneciente a la sociedad civil. La División asesinó a ese hombre porque lo consideraba un peligro y una distracción para la agente que, ahora fugitiva, quiere vengarse. Por otra parte, la División es una creación secreta del gobierno de Estado Unidos para controlar, extorsionar e interferir en política internacional y grandes redes de negocios criminales. Para cumplir su objetivo tiene una aliada, Alexandra Ulinov, caracterizada por la actriz Lyndsy Fonseca, y un contrincante que pasará a ser parte de su equipo con el correr de los capítulos, Michael —Shane West-, con quien tendrá una historia de compañía y amor. Si bien la serie tarda algunos capítulos en marcar una villana, quien mejor encajará en ese papel es Amanda, interpretada por Melinda Clarke.

En este artículo analizamos las relaciones entre el uso de la fuerza y la feminidad en historias de ficción audiovisuales a partir de la serie Nikita (Silverstein, Egilsson y Fink, 2010-2013). Esta perspectiva de estudio comienza al identificar un debate, en el campo de las ciencias sociales, que en gran parte coincidió en definir el ejercicio de la fuerza física y letal como una dimensión de la masculinización de los sujetos. De modo que la violencia quedó adherida, en los estudios de las ciencias sociales, a la masculinidad (Héritier, 2007). El desafío que asume este texto es describir un producto cultural en el que la excelencia y perfección del uso de la fuerza física y letal se proponen en un relato de expresión de la feminidad.

Seleccionamos una serie de ficción que combina elementos de los géneros de acción y novela negra o policiaca. La pertenencia a la acción implica una estética compuesta por efectos especiales - explosiones, incendios, choques, derrumbes-, persecuciones en vehículos o a pie, tiroteos y peleas. El género policiaco aporta historias de policías y criminales, planificación de delitos, uso del engaño y la estrategia. El protagonismo masculino histórico en las ficciones de acción, policiales y — sobre todo- de género negro está abriendo paso desde hace unos años a la incorporación de mujeres. Este proceso justifica la elección de la serie Nikita para este trabajo: la figura de una heroína relativamente autónoma del protagonismo y las historias masculinas.

En este marco de mujeres que protagonizan una narración de delitos, muertes, violencia y profesionalización en el uso de armas y estrategias de combate nos preguntamos de qué modo se les caracteriza. Qué cualidades ponen en ventaja a estas mujeres respecto a otras - y a algunos varones-, qué expresiones de género constituyen debilidades para las misiones y actividades, y cómo se colocan las capacidades físicas de las mujeres en la trama de la narración.

\section{Policías: mujeres y armadas}

Parte de la inspiración para estudiar estos temas surgió de una ilustración que hallé mientras desarrollaba una investigación sobre el ingreso de mujeres a las fuerzas policiales de Argentina. En ese estudio, la relación entre mujeres y ejercicio de la fuerza física y letal era también vital, sólo que incorporaba la complejidad de ser una fuerza autorizada públicamente por el Estado (Calandrón, 2014).

Al realizar el trabajo de campo para aquel trabajo etnográfico, en 2009, me encontré con “Nikita”, una suboficial de la policía de la Provincia de Buenos Aires llamada así por compañeros y jefes, de lo que se mostraba orgullosa. Colegas, jefes y la misma "Nikita" explicaban el uso del indicativo por la belleza, destreza en el mundo policial, efectividad en el trabajo e historia personal de la suboficial. Más allá de los detalles, que no desarrollaremos en extenso en esta oportunidad, su historia personal narra que ingresó a la policía luego de que mataran a su marido, miembro de la policía, en un enfrentamiento violento en la vía pública. Así, la vida 
personal de esta agente de la policía bonaerense era asimilada a la historia de venganza de Nikita.

En este marco, la apropiación de la figura de Nikita en el ámbito de la policía expresaba una reivindicación profesional para las mujeres, puesto que articulaba un tipo de feminidad con habilidades propias del uso de la fuerza pública. En particular, ese tipo de feminidad se sostiene en la belleza física, la sensualidad y la sexualidad. Por ello, en este texto nos concentramos en las relaciones y sentidos entre la feminidad y el uso de la fuerza física que las mujeres de una fuerza policial argentina encontraron y destacan como reveladoras en la historia de ficción de Nikita.

La serie Nikita es un remake de la serie canadiense La femme Nikita (Bonnière et al., 1997-2001), cuya heroína es interpretada por la actriz Peta Wilson. Al mismo tiempo, esta serie está basada en la película francesa Nikita, dirigida por Luc Besson (1990) en la que la actriz Anne Parillaud le pone el cuerpo a la agente protagónica. Aunque las diferencias entre cada edición de Nikita son significativas, todas comienzan con la presentación de una mujer con claras habilidades para el uso de la fuerza física y armada — dominio de la más alta tecnología de espionaje, pistolas, fusiles, escopetas de tiro a distancia, espadas y cuchillos, entre una enorme gama de artículos diseñados para dañar- y una belleza femenina prototípica exaltada en el rostro y el cuerpo.

El primer capítulo de la serie que nos ocupa fue lanzado en Estados Unidos el 9 de septiembre de 2010 por la cadena The CW Network y alcanzó un total de 3.6 millones de espectadores, que marcó un récord entre los debuts de series. Sin embargo, ese éxito de audiencia fue cayendo y a partir de la segunda temporada estaba muy por debajo de los números aceptables para la emisora. La serie continuó cuatro temporadas: las primeras tres con alrededor de 22 capítulos y la final sólo con seis. Esta última fue pensada como un obsequio a los pocos fanáticos que la seguían y esperaban el cierre de la historia.
En Argentina, la serie se estrenó el 2 de noviembre de 2010 por la pantalla de Warner Channel, cadena que televisó todas las temporadas a las 21 horas. Se publicitaba como la serie de una "sensual y peligrosa asesina con sed de venganza”. Si bien tampoco registró éxito en niveles de audiencia, se mantuvo en ese horario destacado de la barra de programación. Con estas características, la serie se convirtió en un icono en especial entre agentes de policía que vieron con admiración la moral profesional, efectividad y sensualidad del personaje.

\section{LAS HABILIDADES DE UNA HEROÍNA}

\section{Transformarse y pertenecer}

En la serie, la pertenencia a la División expone el ideal de agente de las fuerzas armadas o de seguridad volcado sobre todo en la perfección física, el entrenamiento y la estrategia. Si bien la División es una entidad secreta e ilegal, está autorizada por el gobierno de Estados Unidos. Se sugiere una crítica al gobierno y al mundo de la política, que señala, sobre todo, el origen del terrorismo y el crimen organizado en Europa del Este y Rusia.

Un punto de importancia es la idea de transformación de los sujetos como rito de pasaje a un estado distinto, como los rituales analizados con profusión por la antropología clásica (Turner, 1999). Cada integrante de la División fue un peligroso criminal en su pasado, razón por la cual es identificado como valioso. Esta organización, después de un riguroso periodo de formación, los convierte en agentes. Gracias a esta combinación de los dos personajes centrales, los espectadores pueden revivir el pasado de Nikita en la División - y su transformación de civil e incluso criminal a agente de la fuerzapor medio del presente de Alex, la joven rescatada por Nikita que se infiltra en la División para ser su “topo". En la descripción pormenorizada del 
entrenamiento físico extremo, en el aprendizaje del uso de redes de información, explosivos, técnicas de tortura y control de la mentira, vemos el advenimiento de un nuevo estado, característico del género bildungsroman. ${ }^{1}$ Este subgénero de ficción retrata la formación, aprendizaje o evolución física, psicológica, moral o social de un personaje.

Esta estrategia narrativa en ficciones vinculadas a policías se relaciona con interpretaciones que las ciencias sociales hicieron acerca de la institución policial contemporánea. Acerca de policías argentinas, Mariana Sirimarco (2009) mostró cómo las escuelas de formación policial son los dispositivos por los que ese proceso de aprendizaje y cambio se lleva a cabo. En su trabajo, interpreta que la separación entre los novatos y la sociedad civil ocupa un lugar de importancia en la concreción de esa transformación.

En el trabajo intelectual de asociar las investigaciones de las ciencias sociales a las ficciones audiovisuales, Sofía Tiscornia (2009) advierte que el modo en que se producen y reciben historias acerca de la conversión de civil a policía en Argentina y Brasil están atadas a las percepciones sociales de la ciudadanía acerca de sus propias policías. Ésta es una de las diferencias que señala entre El bonaerense (Trapero, 2002) y Tropa de elite (Padilha, 2007). Sin embargo, ambas producciones coinciden en colocar el proceso del pasaje o conversión como un aspecto central del género policial, en cuyas condiciones reside el éxito de la acción profesional de la policía o su fracaso, como en El bonaerense.

“¿Por qué yo?”, pregunta Alex al ingresar a la División, al parecer contra su voluntad. "Porque eres una mujer joven, atractiva y blanca, y virtualmente sin ningún lazo personal ni documentación. Nuestra verdadera atracción es que lograste matar a un criminal que perseguíamos hace tiempo", le responde Michael. La transformación propia del bildungsroman se hace fuerte cuanto más se opone el estado anterior con el posterior: cuanto mayor es el nivel de individualidad, inmoralidad y desorganización, más profundo debe ser el dispositivo de cambio para arribar a una asesina profesional. El diálogo continúa: “¿qué tengo que hacer?”, pregunta Alex. La respuesta es clara: "aprender. Aprender a no hablar como una adolescente adicta, a pararte derecha, a caminar correctamente - la imagen muestra las piernas de Nikita mientras camina con zapatos de tacón-, a hablar correctamente — la toma se detiene en la boca de Nikita, que habla aunque no tenga sonido-. A servir a tu país y no sólo a ti misma".

A cuento de esta última frase, toman relevancia la autonomía e individualidad de la heroína. Una parte de los dispositivos para la transformación falla en Mears, porque no pasa a formar parte de una colectividad en sí. El movimiento es justo el contrario: se separa de ese cuerpo común y sostiene la expresa intención de destruirlo desde las sombras y con la actividad individual. Entonces, si en las ficciones clásicas del bildungsroman la conformación de un cuerpo deja como principal rasgo la aceptación de normas y valores desviados, la separación de él en Nikita provoca la denuncia de esas desviaciones.

Pertenecer a un bando u otro, a la División o su contraofensiva, se valida casi con las mismas reglas comunes en otras ficciones policiales de las últimas décadas. A los personajes los caracteriza la lealtad, la valentía y la capacidad absoluta de infligir dolor y muerte. Entre otras, podemos recordar Robocop (Lynch et al., 1994-1995), Walker Texas Ranger (Canaan et al., 1993-2001), Breaking Bad (Gilligan et al., 2008-2013), Kill Bill (Tarantino, 2003; 2004), Rambo (Kotcheff, 1982; Cosmatos, 1985; MacDonald, 1988; Stallone, 2008). Quienes no ostentan esos atributos quedarán en el camino de la narración, muertos u olvidados.

El bildungsroman es un género conocido como novela de educación, formación o crecimiento, proviene del romanticismo alemán, al que debe su nombre. 
La trama de Nikita comienza con un asunto central: la venganza. Son tres historias lineales de búsqueda de reparación o resarcimiento de una falta pasada. La primera con intenciones de vengarse es Nikita: la antigua agente se rebela contra la División cuando ésta asesina a su pareja por considerarla una distracción al profesionalismo de la heroína. Alex, rescatada por Nikita en un episodio en el que muere toda su familia, busca vengarse de la División porque la considera responsable de esas muertes. Michael será el último en ingresar a la línea de la venganza al informarnos más tarde que la División asesinó a su esposa y su hija. El interés en la venganza es lo que los une en una ofensiva contra la organización a la que alguna vez pertenecieron.

\section{FUERZA ESTÉTICA}

La escena con la que empieza este texto, en la que Nikita reconoce las especificaciones técnicas de un arma de guerra con sólo verla, se reitera a lo largo de la serie: visores térmicos, fusiles de asalto táctico, escopetas de tiro de larga distancia, pistolas de mano, armas blancas y bombas. Como televidentes, nos reconfortará el que Nikita sepa usar esas armas mejor que nadie, además de ostentar el conocimiento técnico acerca de ellas.

Ningún episodio ahorra explosiones y pólvora. Los enfrentamientos físicos y armados se repiten. Llama la atención que a lo escandaloso de los sonidos, detonaciones, balaceras, lluvias de trompadas y patadas se opone la inexistencia de sangre, cuerpos desmembrados y exclamaciones de dolor. Parece tratarse de golpes quirúrgicos asestados por profesionales del rubro. Cada topetazo se acompaña de un sonido seco y de algunos efectos que destacan la rapidez de los movimientos de los agentes en combate. Quienes reciben los golpes se desploman por completo o se recuperan de inmediato, como si el embate hubiera sido sólo un susto, un parpadeo.
Las peleas son rápidas y limpias. Así como evitan la sangre y los moretones, no hay lugar para la agonía eterna de los luchadores ni los insultos. Son peleas puras, en el aspecto estético.

En una escena de golpes, seguimos a la protagonista: primero se encuentra con dos corpulentos agentes de la División — casi tan entrenados como ella-, se defiende con patadas al frente y atrás, un golpe certero deja fuera de juego a uno de ellos. En el forcejeo con el otro, Nikita recibe un golpe en la nariz que no deja marcas y que sólo la impulsa a golpearle la cabeza reiteradas veces contra la mesa. Luego se cruza con un guardia privado al que desactiva con dos patadas sucesivas en el pecho. Ingresa a la habitación de un mandatario y le dispara con un arma de descarga eléctrica. Lo coloca en una camilla y lo saca del hotel al mismo tiempo que escapa a obstáculos y tiros. Estas situaciones son frecuentes. Ella no atraviesa un momento de congoja, culpa o tristeza por la fuerza letal infligida. Sólo la aplica y lo hace con armas específicas o simples elementos contundentes que transforma en armas circunstanciales.

La cualidad del uso efectivo de la fuerza en las mujeres es una novedad del cine y la televisión de la década de 1990. Hasta entonces las mujeres podían ser poderosas y malvadas, pero su poder procedía de artes específicas: “el engaño, el ataque indirecto y la ocultación de los deseos propios, tal como corresponde a los débiles” (Bernárdez, 2012: 93). También en las policías de Argentina se registra un movimiento similar en relación con el proceso histórico de incorporación de mujeres. Las primeras en ingresar a la fuerza fueron destinadas a los sectores de la investigación criminal y el registro de delincuentes (Calandrón y Galeano, 2013). Esto sucedió a finales del siglo XIX, cuando se asignaron mujeres a las tareas de inteligencia, puesto que la astucia femenina para engañar y seducir a los hombres para llevarlos hasta las garras de la policía era un "don" que podía ser utilizado por la institución sin controversias. En cambio, el ingreso a las tareas operativas 
asociadas al uso de la fuerza física y letal — con la portación de armas, uso de uniforme e intervenciones operativas - llegó varias décadas más tarde. Al parecer, el desempeño en estas actividades fue terreno de debates y disputas, y sólo se concretó después.

¿De dónde proviene la fuerza física de Nikita? Algunas series que colocan heroínas en el centro de su argumento insinúan explicaciones sobrenaturales de la capacidad física de esas mujeres. Éste es el caso de Terminator (Cameron, 1984; 1991), filme en el que Sarah Connor exhibe aptitudes corporales y marciales originadas de una anomalía. Se trata de una deformación psíquica y cultural de la feminidad vuelta, entonces, una capacidad guerrera única (Molia, 2012). El origen de la fuerza y la capacidad de matar de Mears no es sobrenatural, no es una mujer extraordinaria. No se trata de una anomalía sino de un proceso de aprendizaje en la academia y arduo entrenamiento. Esto deviene en la humanización de la protagonista, cualidad que la distingue de otras ficciones, como la nombrada Terminator, pero la acerca a la Beatrix Kiddo - la Novia o Mamba Negra— de Kill Bill (Tarantino, 2003; 2004).

¿Qué cualidades distinguen a Nikita de sus oponentes? El prejuicio. Sus habilidades técnicas y físicas causan sorpresa porque no muestra las debilidades esperadas — desde las expectativas de sus contrincantes - para una luchadora mujer. Lo que la diferencia de los varones a quienes se enfrenta es que esperan de ella —una mujer- menos resistencia y fuerza, y por qué no, misericordia hacia un combatiente a punto de rendirse.

\section{CORPORALIDAD, BELLEZA Y ADMINISTRACIÓN DE LA SEXUALIDAD}

\section{Mujeres fatales}

La conquista de los papeles protagónicos por parte de mujeres representa un fenómeno más o menos nuevo en ficciones audiovisuales de acción en el mainstream cinematográfico y televisivo. Con más precisión, a partir de la década de 1990 fueron incorporadas a este género fílmico. Blázquez (2003) hace una caracterización sintética, útil para situarnos: una completa ausencia de protagonistas mujeres en la década de 1980, con la saga Rambo (Kotcheff, 1982; Cosmatos, 1985; MacDonald, 1988; Stallone, 2008) como fiel ejemplo de ello, seguida de una aparición gradual en los años siguientes, cuando las mujeres comenzaron a tener papeles de novias o amantes de los protagonistas varones. Más tarde, hacia finales de la década de 1990, aparecerán mujeres en papeles activos en los que llegaban, por momentos, a igualar la acción de los varones, pero al final cedían el clímax heroico a favor de una figura masculina. Hasta aquí las mujeres eran buenas compañeras y novias necesarias frente al objetivo de romantizar el género de acción. La relación de compañerismo entre mujeres y varones en estos últimos tipos de películas estaba abocada sin remedio a un romance heterosexual. Justo ese condimento de relaciones heteroamorosas y sexuales permite entender la llegada de mujeres a la acción cinematográfica, impulsada por una mirada masculina y heteronormativa sobre las mujeres y los vínculos (Blázquez, 2003).

La incorporación de heroínas en el cine exigió otorgar a esas figuras femeninas autonomía, poder de decisión y un papel activo en la resolución de los problemas que planteaba la trama. Exigía, en suma, personajes diferentes a aquellas compañeras y novias que se derretían frente a los logros, bondad y fortaleza de los héroes masculinos. Ese movimiento provocó algunas dislocaciones respecto a la sexualidad y los deseos amorosos de estas mujeres, que se alejaron del modelo tradicional. En la composición de las heroínas, la ambigüedad sexual compite con las fantasías del amor romántico en las que las mujeres entregan su protagonismo y su espíritu de aventura por el compromiso y la familia futura.

Yvonne Tasker (1998) encuentra tres tipos de heroínas en el género de acción, una clasificación útil 


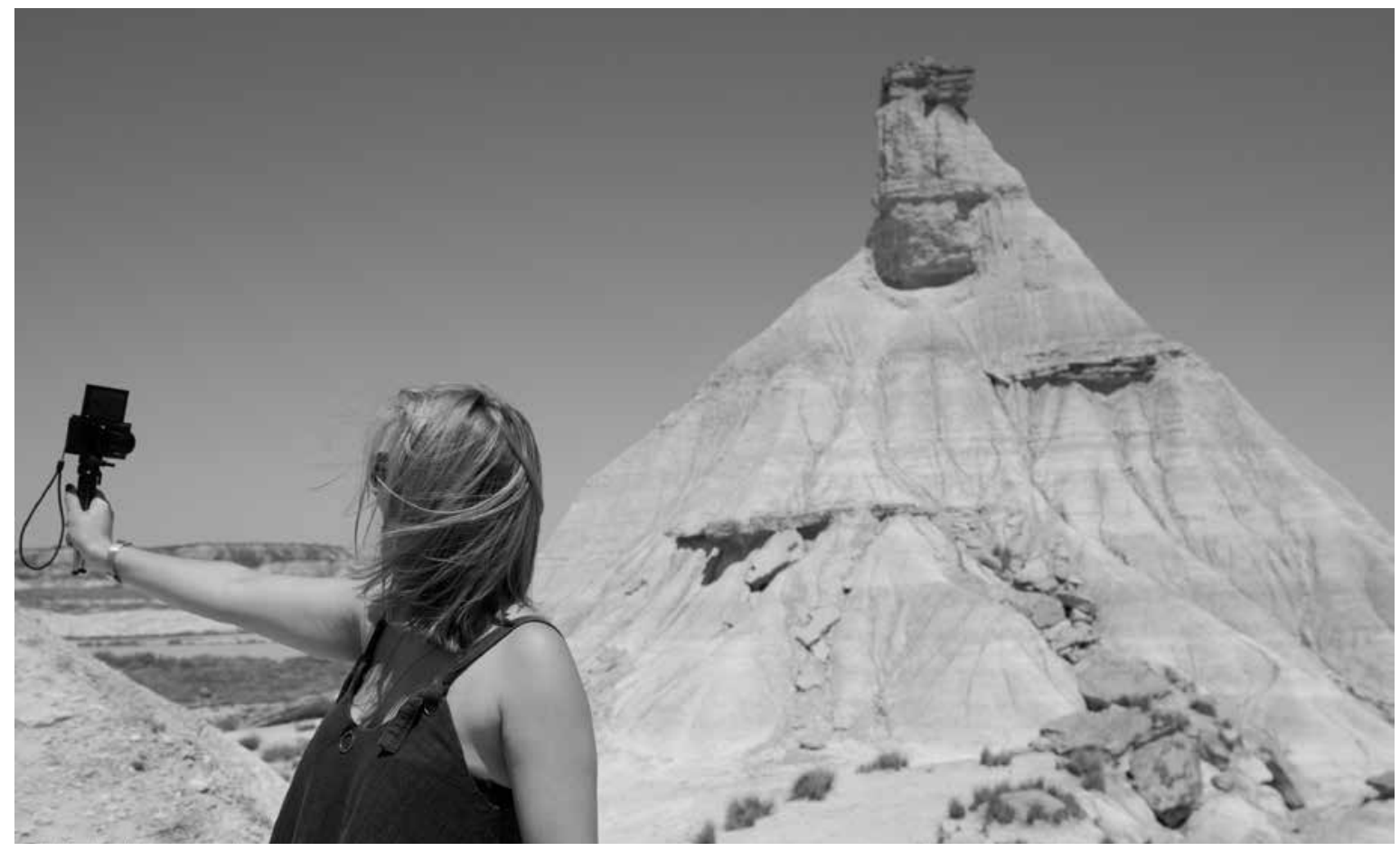

Mario Antonio Pena Zapatería Y Youtuber Maialen, julio de 2017.

para agrupar las características generales vinculadas a la representación de género y sexualidad de los personajes, pero que de ningún modo son fijas y cerradas en las narraciones. El modelo tomboy — traducido al español como "chicazo" — proviene de la variación de un modelo mayor, el "cine de chicos". Para Halberstam, poco importa qué hacen esos chicos:

Pueden estar creciendo o rechazar hacerlo, vincularse a una mascota o torturarla; pueden estar jugando con extraterrestres, luchando por sobrevivir sin un padre o una madre o ambos, listos o tontos, estar abandonados o reunirse con una familia. La eterna popularidad de las películas de chicos sugiere que la transformación del chico en un hombre es muy interesante para esta cultura (2008: 296).

La niña tomboy es una figura adolescente atravesada por el descubrimiento de la sexualidad femenina que se encuentra en crisis y se reestablecerá en el desenlace de la narración hacia el orden heterosexual y de feminidad tradicional dominante. Las tomboy presentan, en la ficción, una personalidad desafiante que no encaja por completo en el modelo de feminidad ni masculinidad ofrecida en el relato del que forman parte, sino, al contrario, que mezcla elementos que originan una expresión de género nueva.

La otra forma en que aparecieron las heroínas en las narraciones de ficción fue tras la silueta de la buch femme, caracterizada por una marcada masculinidad, de nuevo, definida en el contexto de los significados de género de la ficción en la que aparecen. Esta figura proviene, sobre todo, del cine independiente, preocupado por narrar historias no convencionales o ridiculizar ciertas "desviaciones de género" condenadas en la buch. Para Halberstam (2008), ese tipo de personaje experimentó un cambio desde la ridiculización, el señalamiento de la 
monstruosidad y las depravaciones, hacia la toma de un lugar reivindicativo de las diversidades sexuales y genéricas. La buch suele fumar puros, usar armas, seducir a mujeres jóvenes y femeninas, al tiempo que se desempeña en trabajos no convencionales, como pistolera, carcelera, miembro de una banda o proxeneta. Por último, Tasker (1998) señala que la feisty heroine es el otro modelo en el que se presentan las heroínas mujeres. Romántica, hipersexualizada y a veces objeto sexual en el relato fílmico. Es una "chica mala", en esencia, por el coraje que exhibe y con el que resuelve los acontecimientos.

En la serie Nikita (Silverstein, Egilsson y Fink, 2010-2013), los personajes de mujeres están compuestos con elementos de los tres tipos de heroínas definidas por Tasker (1998) y Halberstam (2008). Aunque se centra en especial en el feisty heroine. Cientos de escenas comienzan en la piel de Maggie Q, la cámara la recorre semidesnuda, con ropa interior o en traje de baño. Cuando llega el momento de cubrirse, lo hace con prendas elegantes y entalladas que realzan sus curvas y la ayudan a lucir su altura y delgadez. Esto convive con el coraje, una personalidad que se basa en la seguridad propia y una actitud desafiante, propias del modo en que han sido compuestas las mujeres buch. Con la actriz Lyndsy Fonseca, además de exaltar la belleza de su rostro y cuerpo, marcado por el entrenamiento físico, la serie propone la juventud como rasgo de belleza. Este personaje tiene una buena dosis de la tomboy, pues atraviesa un proceso de descubrimiento de sí misma y tensiones sexuales.

No pasa inadvertido el componente racial en los cuerpos de las mujeres, cuestión que coloca la belleza fuera del centro del modelo dominante hollywoodense de mujer blanca. El cruce étnico se pone en juego con los rasgos orientales de Magui Q y las historias de mujeres de origen familiar eslavo — piel blanca y ojos claros- que actúan Fonseca y Clarke, así como con Tiffany Hines en el papel de Jaden, como una joven recluta afrodescendiente. En varios pasajes, como el citado al comienzo de este texto, la serie propone un vínculo entre la sensualidad y el uso de las armas, una peculiaridad utilizada por lo general para elaborar los personajes de mujeres buch en el cine. Al igual que éstas, Nikita, Alex, Amanda y Jaden golpean, matan, usan las armas, tienen un pasado criminal y de adicciones, lideran bandas criminales y la estética narrativa hace de eso un signo de sensualidad.

Como un efecto opuesto al que ellas generan en los hombres de la serie, las bellas mujeres parecen no enamorarse. Durante buena parte de la primera temporada ningún personaje parece interpelarlas en el aspecto afectivo. El único personaje por el que se preocupa cada una de ellas es la otra. Esto produce un clima homoerótico sostenido en sentimientos de cariño, protección e interés que se expresan en el marco del vínculo de amistad y asociación profesional. Podríamos relacionar estos rasgos con algunas características de las mujeres tomboy en cuanto a lo transicional y el misterioso silencio en torno a la sexualidad de estas mujeres. Este detalle es el que destacaban las agentes policiales de Buenos Aires, atraídas por la historia de Nikita: en ella reconocían que su propio gusto por "arreglarse" y "ponerse lindas" no se oponía al mundo profesional erigido sobre la capacidad de hacer uso de la fuerza física. Gracias a este rasgo, lograban responder a una crítica social que acepta la profesionalidad policial sólo en cuerpos masculinizados, y para la cual, por el contrario, expresar feminidad sería mostrar debilidad profesional.

Con el correr de los episodios, cede esa inmunidad sentimental y la atracción física hacia los hombres aparece. Se instalan, como un atractivo de la serie, el amor y las relaciones heterosexuales. Recién allí descubrimos a Shane West en el papel de Michael, un integrante de la División que entrenó a Nikita en el pasado y la caza en el presente, además de estar a cargo de todos los reclutas, incluida Alex. Cuando se transmitía la serie, West era reconocido en Estados Unidos como un 
galán consagrado, en especial en la oferta televisiva orientada a jóvenes. No obstante, y a pesar de mostrar desde el principio de la serie un claro interés por Nikita, tarda varios capítulos para enfocarse en ella como su blanco de atracción. Parece, sin embargo, atraído por la belleza y juventud de Alex. A diferencia de la exhibición del cuerpo de las mujeres en su vida cotidiana, en el despliegue físico de las actividades armadas y en los entrenamientos - en los que se realza la figura, agilidad y musculación de las actrices-, la imagen de Michael permanece sobria e insípida durante varios episodios.

Para visualizar el poder físico y la firmeza al llevar a cabo las acciones violentas, analizaremos un fragmento de una de las misiones. El escenario es un desfile de modas en el que Nikita se infiltra sin problemas. Se notan flashes de cámaras, cambiadores de ropa, modelos a medio vestir y organizadores que hablan por celular. La agente va vestida con un traje clásico y elegante que completa su aspecto empresarial, compuesto por lentes, pelo lacio apenas recogido hacia atrás, una carpeta, falda y zapatos de tacón. Camina directo hacia una mujer y le dice que es la compradora de una marca. "Pensé que vendrías la semana que viene", le dice la señora Miles, dueña de la empresa que organiza el evento. "Lo sé, cambió nuestra planificación, espero que no sea problema”, contesta amable Nikita. Mientras caminan entre los percheros de ropa la agente mira los vestidos y los halaga, "increíbles". Sin embargo, con el mismo tono amable comenzará a decirle a Miles que conoce sus negocios con tráfico de esclavos, que conoce el accidente reciente en los talleres textiles y sabe quién le provee de ese tráfico. La mujer se pone nerviosa, niega en principio algunas de las afirmaciones de Nikita, que le hace una llave palanca con los brazos y la deja de espaldas. La cámara las toma de frente, se ve en primer plano el rostro de la señora Miles que muestra dolor y detrás de ella, Nikita que no exhibe un gesto que no sea tranquilidad. Nadie nota el forcejeo a pesar de que el lugar está regado de gente. Nikita la suelta y le pide a gritos que le diga dónde está el taller. Quedan frente a frente, la señora Miles, despeinada y agitada, le pide que se vaya. Lejos de esto, Nikita la toma con una mano por el cuello. No hay señas de que Miles pueda escapar. La ex agente reitera que quiere la ubicación del taller. La escena termina.

A pesar de la fuerza física, como en la escena con Miles, y el uso de armas letales, como en el intercambio con Trevor, las estrellas de la serie también cuentan con un elemento que les da el toque final. Las mujeres pueden infiltrarse en el mundo de la moda, como si fueran una integrante más. Asisten a fiestas de etiqueta con un atuendo que no le envidia nada a otras concurrentes. Sin temores, participan en una subasta de joyas preciosas exclusivas y son capaces de conversar y compartir opiniones con otras personas interesadas en esos elementos suntuarios. La belleza, elegancia y sus modos refinados les abren la puerta a las misiones más difíciles. Combinan la fuerza física, típica de la masculinidad en el género de acción, como la buch, con la astucia, el engaño y el disimulo, atributos siempre más disponibles para la caracterización de personajes femeninos.

\section{DESTREZA FÍSICA, ENTRENAMIENTO Y CORPORALIDAD}

Uno de los capítulos de la primera temporada comienza con un concierto de trompadas entre las dos protagonistas. Se escuchan golpes de puño y patadas que alcanzan el cuerpo de la compañera y algunos gemidos para impulsar la descarga de cada uno, casi como en un partido de tenis, en sus últimos sets. El atuendo de ambas es deportivo. El detalle del pelo suelto de Nikita, relativamente incómodo para la lucha, le da frescura, a diferencia del de Alex, que lo lleva recogido y la muestra más comprometida con el asunto. De los cuerpos apenas se ven los brazos de Alex. Si bien la ropa es ceñida, no exagera las curvas 
ni la cámara se detiene en otro lugar que no sean sus rostros. Cada dos o tres golpes Nikita muestra un cartel con una palabra y Alex la define de inmediato. Son palabras que indican lugares y códigos que utiliza la División, con lo cual se señala que se trata de una particular clase de estudio. Lanzan los golpes, giran sobre su cuerpo, se tiran al piso y se levantan de un salto. Hay patadas perfectas, saltos y giros aeróbicos — mortal adelante y atrás, roles adelante por encima del otro cuerpo, media luna o rueda- Los cuerpos de ambas mujeres vuelan. Todos los golpes hacen contacto con el cuerpo al que se enfrentan, no hay errores. En el movimiento final, Nikita saca de combate a la joven, la expulsa con las manos hacia atrás y la interpela: "vamos, Alex, despierta". "Estoy despierta, sólo estoy exhausta", responde Alex, a quien recién ahora se la nota cansada. Al contrario, Nikita ni siquiera respira con dificultad.

Estos interludios de preparación gimnástica son comunes. En las luchas se cruzan varones con mujeres sin grandes diferencias. Los cuerpos aparecen apenas transpirados.

Las escenas de entrenamiento se utilizan para exaltar la musculación de actores y actrices y para colocar la preparación y el ejercicio como temas nodales de las historias. Acerca de los físicos de varones, no veremos cuerpos exuberantes y venosos del estilo de Rambo, Rocky o Terminator. La estética corporal masculina ha modificado sus parámetros desde los héroes de las décadas de 1980 y 1990 a la actualidad. La hipermusculación y la voluminosidad cedieron lugar a la delgadez, la agilidad y el equilibrio. Ya no son los cuerpos hercúleos, al estilo del culturista Schwarzenegger, los elegidos para protagonizar tramas de acción; sino los fibrosos y moderados que manifiestan el dinamismo y la velocidad más que la fortaleza.

Por el lado de las mujeres, las cosas han sido distintas. Si bien no hay razón basada en la naturaleza ni en ningún componente invariable de la cultura por la que los cuerpos de varones y mujeres deban comprenderse como dos fenómenos a priori diferentes, es notable que en el campo de las ficciones audiovisuales hegemónicas, producidas sobre todo por la industria estadounidense, han sido tratados y fabricados de formas desiguales. De igual modo, las instituciones que ejercen la fuerza pública — como muchas otras - se han preocupado por reglamentar los cuerpos en relación con una ubicación de género previa. Por ejemplo, al requerir medidas de estatura y peso distintas para el ingreso, exigir rendimiento físico diferencial y vestir los cuerpos con uniformes que identifican dos géneros: masculino y femenino (Pruvost, 2008b). En ambos campos, el de las producciones audiovisuales y el de la institución policial, los requisitos ordenan y construyen cuerpos diferentes. En este marco, colocamos algunas de las transformaciones en la construcción de cuerpos hegemónicos de las mujeres habilitadas para ejercer la fuerza que, desde nuestro punto de vista, fueron trastocados de una forma distinta a la de los cuerpos de varones que mencionamos en el párrafo anterior.

Un movimiento que excede el ámbito del cine es la creciente delgadez de los cuerpos de las mujeres como un proceso continuo. A principios del siglo XX, el mundo de la moda señalaba como bellos los cuerpos ni demasiado gruesos, ni demasiado delgados (Kaczan, 2012). Las prendas de vestir apuntaban a comprimir la cintura, muchas veces con la ayuda de un corsé, levantar busto y acentuar las caderas prominentes. Esa misma prenda era solidaria con la postura erguida y la apertura del pecho. Por otra parte, se conservaban hombros pequeños que no sobrepasaban el ancho de las caderas y la dimensión del tórax quedaba cubierta por el tamaño de los pechos. Las actividades deportivas y el entrenamiento modificaron estos parámetros, y los cánones de belleza incorporaron hombros más desarrollados, brazos delgados y fibrosos, senos de menor tamaño en relación con una espalda producto del desarrollo de los músculos dorsales del tronco. Así como Maggie Q, Angelina 
Jolie se sumergió en un arduo entrenamiento físico para interpretar a Lara Croft en Tomb Raider (West, 2001; De Bont, 2003) y Michelle Rodríguez para hacer lo propio con el personaje Letty Ortiz de Rápido y furioso (Lin, 2013). No decimos que se trata de un movimiento lineal y generalizado del cambio en los cuerpos hegemónicos de mujeres en audiovisuales de acción, sino de elementos que expresan variaciones en la corporalidad de las heroínas.

Así como los físicos masculinos resignaron los efectos de fuerza para buscar efectos de agilidad y destreza, la delgadez de las mujeres incorporó rasgos, en la propia musculatura, para demostrar firmeza.

\section{LA SEXUALIDAD, UN ARMA DE GUERRA}

La cámara de desliza y sigue los pies desnudos de Nikita. Lleva una bata corta y se seca el pelo. Acaba de ducharse. Por la bata abierta se ve su ropa interior con encaje. Suena música pop. Nikita revisa la computadora, recibe información de su espía secreta y va hacia un perchero repleto de vestidos, algunos aun protegidos con bolsas. Elige uno, lo separa y gira su cuerpo hacia un maletín. Con la misma delicadeza mira las armas que están adentro, dispuestas en orden. Toma una pistola automática. Suena la misma música pop. Tira del cerrojo para atrás, carga la bala en recámara, la mira y levanta su vista hacia adelante, con el rostro limpio, sereno y el pelo aún algo despeinado.

La sensualidad de las mujeres de la serie está unida a las actividades brutales y asesinas del medio en el que viven. Abundan imágenes en las que la protagonista acaricia, roza con suavidad y se acerca a la boca las armas de fuego. La música ayuda en estos clímax.

La serie coloca el atractivo de las mujeres entre las tantas capacidades que tienen para las misiones. En sobradas ocasiones, las operaciones criminales están coordinadas por varones, el mundo de los negocios

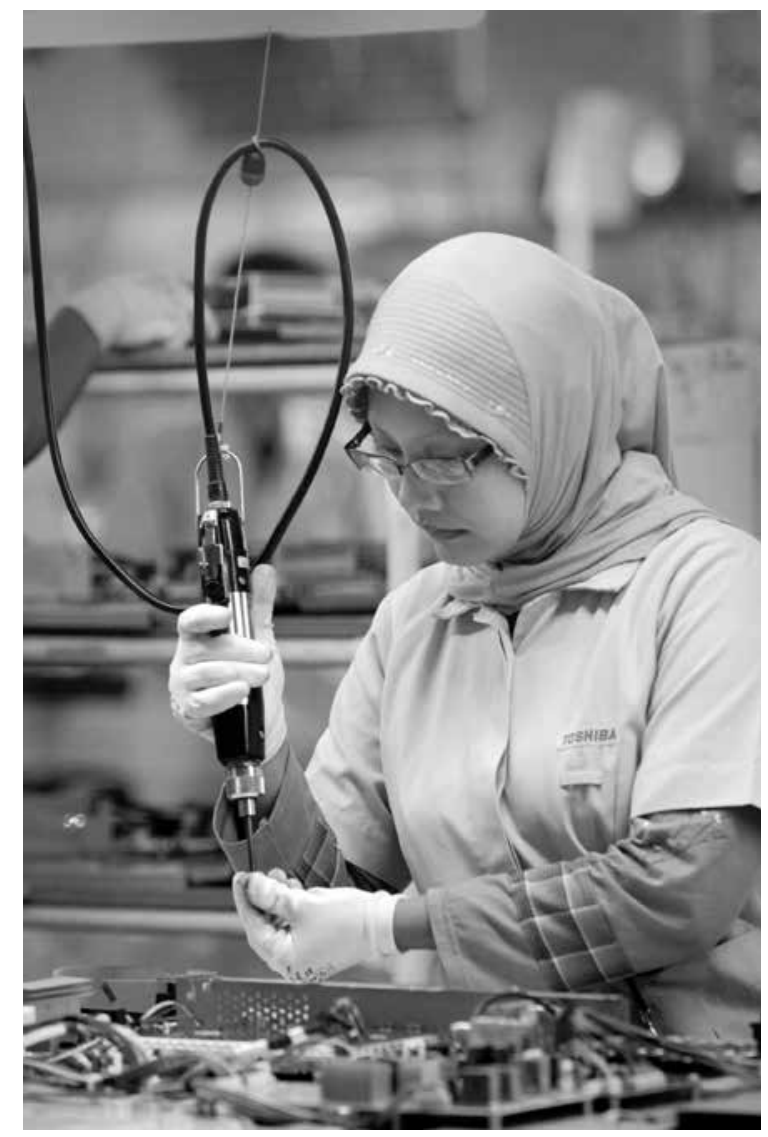

Asrian MirZa/Organización Internacional del Trabajo • Trabajo femenino en una fábrica de aparatos electrónicos. Cikarang, Indonesia, diciembre de 2007.

está colonizado por señores desalineados, obesos y adictos, proclives a establecer acercamientos sexuales con cualquier mujer que se les aproxime. En este mundo se infiltran Alex, Jade y Nikita, y se abren paso para sabotear los crímenes con su sensualidad.

En más de una oportunidad han ingresado a las zonas de combate o a información porque esos mismos personajes masculinos las "eligen" como compañías sexuales o intentan seducirlas. Ellas parecen dejarse convencer, entran en los espacios delictivos, establecen conversaciones y de inmediato los atacan y logran su objetivo. Los juegos sensuales no llegan, en ningún caso, a concretarse más que en besos y caricias, 
y se alejan del intercambio sexual entre las heroínas y los criminales. La sensualidad se utiliza como una puerta de entrada para más tarde romper con el pacto.

Una constante de estos personajes es la sexualización de la actividad profesional, pero se trata de una sexualización particular. En primer lugar, porque está administrada, lo que significa que la vida sexual no invade el terreno del trabajo, sino que es introducida con fines específicos. Se utiliza en la medida en que ayuda a la concreción de una misión. En segundo lugar, esa administración está a cargo de las agentes. En los casos en los que se pierde ese control, el orden se restablece gracias a la intervención de ellas mismas. En tercer lugar, porque al ser de uso exclusivo de las mujeres, las coloca en un lugar de poder respecto a los varones, ya sea porque es una habilidad con la que no cuentan los agentes varones o porque doblega a los criminales deseosos y débiles frente a la sensualidad femenina.

La puesta en juego de la seducción no se mezcla con la moral sexual de los personajes, sino que aporta a la constitución de su moral profesional. Con esto queremos decir que la administración de los juegos de seducción es parte de las herramientas técnicas y el uso más eficaz de éstas deriva en una actuación policial mejor valorada. Para las instituciones policiales, el control de la sexualidad y el erotismo ha sido un tema de sumo interés desde el ingreso histórico de mujeres (Pruvost, 2008a). En particular, para las agentes policiales de Buenos Aires que encontraban en Nikita una figura contestaria a las críticas sociales que recibían, las relaciones y evaluaciones de la sexualidad son una forma legítima de regulación de la moralidad profesional (Calandrón, 2014). Es posible que parte de la identificación con esta ficción resida en que, desde la mirada de las agentes, en los espacios de trabajo cotidianos de la policía bonaerense, la sexualidad no está — tampoco- negada ni negativizada, sino puesta al servicio de la constitución de prestigios, reputaciones y carreras profesionales.

\section{Valores morales: el lugar del amor romántico, la familia y el bien común}

La serie nos ofrece una mujer autónoma, sin lazos familiares o amorosos intensos. Alex es la única relación de cercanía de la agente, trazada por cierta dependencia de la joven. Sin vínculos fuera de la División, cultiva la individualidad y la libertad extrema en cada capítulo.

Aunque la narración no deposita en la historia personal de las protagonistas el deseo explícito de una familia nuclear clásica, este tema aparece como importante en los valores morales que guían las misiones. En las intervenciones armadas podemos ver que la defensa de los vínculos familiares y la protección de los niños son principios rectores. La inclusión de esta ética familiar es uno de los elementos que distingue a los criminales inmorales de los agentes morales, a pesar de que utilizan los mismos medios para la acción.

La oposición entre la vida familiar y la individualidad está en el origen de la historia. Todos los miembros de la célula secreta ingresaron a partir de una tragedia que quebró sus propias familias. La División asesinó al hombre que estaba comprometido con Nikita, hizo explotar el auto en el que iban la esposa y la hija de Michael, y asesinó a toda la familia de Alex. La División funciona gracias a la ruptura de los lazos afectivos superiores de sus agentes, relaciones de dependencia e historias de identidad. La autonomía se torna una forma de ser en la ficción, cualidad central y distintiva de Nikita, gracias a la separación emocional de su persona respecto a la sociedad civil. Sin embargo, el conjunto de sus misiones está al servicio de la defensa de las familias, tanto en la integridad de hijos, padres y madres, como de valores morales familiares.

Nikita narra: "me entrenaron como una asesina profesional. Hasta que rompí una regla: me enamoré. De un civil. Se llamaba Daniel. Después de tres meses juntos lo único que quería era estar 
con él, tener una vida normal. Pero en la División no puedes tener eso, así que lo mataron e hicieron que pareciera un accidente", mientras la vemos caminando por un cementerio. Rodeada de lápidas, se detiene frente a una en la que se lee "Daniel Monroe". Se arrodilla frente a ella y la nitidez de las imágenes se difumina en blanco lo que genera la sensación de un recuerdo que lleva a la reconstrucción de la historia personal pasada.

El amor romántico heterosexual se coloca como la causa que desata el objetivo de la búsqueda de revancha. Vengar ese amor, ahora idealizado, es lo que mueve, en primer lugar, a la agente. Allí el personaje toma el papel de futura esposa o novia a quien le arrebatan el amor verdadero. Sin embargo, ese lazo de amor es el que, desde la postura de la División, debilitaba a Nikita. Decidieron matar a su novio para que la agente se concentrara sólo en sus operaciones policiales, no se distrajera y no desarrollara intereses superiores. De cualquier modo, esta escena de recogimiento, recuerdo y dolor por la muerte de la pareja sirve para conocer la respuesta de Nikita a esa posición sobre el amor. Aún de rodillas y llorando, monta un escenario para dar un golpe a la División, lo que contrarresta la idea de distracción a causa del amor. Este segundo elemento es el que quisiera destacar en la descripción de uno de los capítulos.

El discurso hegemónico que recoge la ficción señala al amor como una debilidad para las mujeres y se corresponde con una postura disruptiva en la que se percibe como un prejuicio — de género, podríamos agregar-. Además, la mujer protagonista administra esas descalificaciones de género, las utiliza y las convierte en fortalezas.

A partir de ese amor, origen de la narración, el romanticismo heterosexual irá ganando lugar en la serie con la incorporación de Michel y el desarrollo de la historia de Alex. Se muestra la convivencia de la pareja y la compañía amorosa con la efectividad profesional. Esta forma de presentar el amor y la venganza también era, para volver al trabajo de campo etnográfico que inspiró el análisis de esta serie en particular y del personaje en general, un rasgo que interpelaba a las mujeres policías que llamaban Nikita a su compañera. Más allá de los detalles de la historia de esta suboficial, su entorno y ella misma entendían que la muerte y el daño en el amor de pareja la movilizaban a tomar acciones de reparación asociadas a su integración a una fuerza de seguridad para la protección de otras vidas — otros maridos, hijos, padres y madres - y la conjuración y control de operaciones delictivas. En este marco, resulta interesante la lectura compartida por los dos mundos de significados acerca de la transformación del dolor en un sentimiento humanamente superior susceptible de convertirse en un marco moral legítimo para el uso de la fuerza.

\section{Conclusiones}

En el desarrollo de este artículo analizamos sentidos acerca de la relación entre el uso de la fuerza física y las feminidades en una historia de ficción. La lectura e interpretación de esa relación estuvo orientada por un ejercicio antropológico en una fuerza de seguridad argentina y la figura particular de mujer policía, por medio del cual tematizamos la narrativa ficcional. Combinar un relato literario con el relato de la etnografía es un desafío que, sin embargo, no tratamos de resolver por las coincidencias entre ambos ni por el marco de interpretación de la narrativa ficcional como una ilustración de la etnografía, ni ésta como la explicación de la otra. En cambio, el marco en el que hicimos dialogar los dos tipos de productos es la construcción de significados capaces de interpelarnos como agentes sociales —en particular, a mujeres policía-, expresar problemas sociales y críticas, y elaborar respuestas o rechazos a esas críticas, que quedan disponibles en una cultura comunicacional mayor. Ponderamos el poder 
de la imaginación para crear discursos y figuras en relación con el uso de la fuerza por parte de mujeres, incluido tanto en una serie de ficción como en relatos etnográficos, sin perder de vista que cada uno se relaciona de modo particular con el que llamamos el "mundo real" (Fassin, 2014). No es menor, incluso, que ese poder de imaginación deje expresar un modelo posible o ideal de mujer policía con el que dialogan mujeres miembros de la Policía de la Provincia de Buenos Aires.

La feminidad elaborada para presentar a la protagonista de la serie se monta sobre la combinación de la fuerza física, el poder letal, la inteligencia y la belleza. Conviven, en un mismo personaje, una cualidad que de manera histórica definió a los héroes varones - la fuerza física - con otras con las que se clasificó la incorporación de mujeres a la pantalla de acción - la belleza y el romanticismo-.
Éste es, quizá, el rasgo principal de la serie, una heroína multifacética, compuesta con elementos utilizados por lo regular para caracterizar géneros y sexualidades distintas.

La serie evita asociar de manera lineal la belleza física, el gusto por la moda y el deseo de un amor romántico con la debilidad. Al contrario, utiliza ese prejuicio social para quebrarlo y potenciar a la heroína. El estereotipo social de la belleza femenina como contracara de la debilidad es el que han encontrado las mujeres policías. Nikita es parte de una configuración de elementos útil para formular una crítica y defender su actividad profesional, centrada en el ejercicio efectivo de la fuerza física, tanto como para construirse y encontrarse en un tipo de feminidad que articula la belleza, la sexualidad, el coraje y los afectos. D

\section{Bibliografía}

Bernárdez Rodal, Asunción, 2012, "Modelos de mujeres fálicas del postfeminismo mediático: una aproximación a Millenium 1, Avatar y Los juegos del hambre", en Anàlisi, núm. 47, pp. 91-112.

Blázquez Chaves, Esther, 2003, “Las 'nuevas' heroínas del cine de acción: Lara Croft y Los Ángeles de Charlie”, en Asparkía, Investigació Feminista, núm. 14, pp. 71-81.

Calandrón, Sabrina, 2014, Género y sexualidad en la policía bonaerense, Universidad de San Martín Edita, San Martín.

Calandrón, Sabrina y Diego Galeano, 2013, “La 'Brigada Femenina'. Incorporación de mujeres a la Policía de la Provincia de Buenos Aires (1947-1955)”, en Ricardo Salvatore y Osvaldo Barreneche (eds.), El delito y el orden en perspectiva histórica, Prohistoria, Rosario.

Corleto, Julieta di, 2012, "Flor de fango: la mujer delincuente en el cine argentino (1930-1950)", en Imagofagia, núm. 6. Disponible en línea: <http://www.asaeca.org/imagofagia/index.php/imagofagia/article/view/279>.

Fassin, Didier, 2014, "True Life, Real Lives: Revisiting the Boundaries between Ethnography and Fiction”, en American Ethnologist, vol. 42, núm. 1, pp. 40-55.

Halberstam, Judith, 2008, "Pinta de butch. Una guía dura de las butches en el cine”, en Judith Halberstam, Masculinidad femenina, Egales, Barcelona.

Héritier, Françoise, 2007, Masculino/femenino Il: disolver la jerarquía, Fondo de Cultura Económica, Buenos Aires.

Kaczan, Gisela, 2012, "Figuras femeninas en la mira. Cuerpos, vestidos, imágenes en las dos primeras décadas del siglo xx", en Mora, núm. 18, pp. 11-28. Disponible en línea: <http://revistascientificas.filo.uba.ar/index.php/mora/article/view/323>.

Molia, François, 2012, "Qu'est-ce qu’une femme? Evolution du personnage féminin dans la série Terminator", en Coline Cardi y Geneviève Pruvost (dirs.), Penser la violence des femmes, La Découverte, París.

Pruvost, Geneviève, 2008a, De la "sergote" à la femme-flic. Une autre histoire de l'institution policière (1935-2005), La Découverte, París.

__ 2008b, "Quand le statut policier est avant tout stature: corps féminins et corps masculins face au recrutement policier (1935-2005)", en Jean-Marc Berlière, Catherine Denys, Dominique Kalifa y Vincent Milliot (dirs.), Métiers de pólice. Être policier en Europe, XVIIleXXe siècle, Presses Universitaires de Rennes, Rennes, pp. 453-465. 
Sellier, Geneviève, 1999, “Images de femmes dans le cinema de la Nouvelle Vague”, en Clio. Femmes, Genre, Histoire, núm. 10. Disponible en línea: <https://clio.revues.org/265>.

Sirimarco, Mariana, 2009, De civil a policía: una etnografía del proceso de incorporación a la institución policial, Teseo, Buenos Aires.

Tasker, Yvonne, 1998, Working Girls: Gender and Sexuality in Popular Cinema, Routledge, Londres.

Tiscornia, Sofía, 2009, "Vida de policías, códigos morales y derechos humanos. A propósito de los filmes Tropa de elite (José Padilha, 2007) y El bonaerense (Pablo Trapero, 2002)", en Sofía Tiscornia, Roberto Kant de Lima y Lucía Eilbaum (orgs.), Burocracias penales, administración institucional de conflictos y ciudadanía, Antropofagia, Buenos Aires.

Turner, Victor, 1999, La selva de los símbolos, Siglo XXI Editores, Madrid.

\section{Filmografía}

Besson, Luc (dir.), 1990, Nikita, Les Films du Loup/Cecchi Gori Group Tiger Cinematografica, París.

Bonnière, René, Chris Gross, Jon Cassar et al. (dirs.), 1997-2001, La femme Nikita, serie de televisión, CTV Television Network/LPN Productions Inc./Fireworks Entertainment/Baton Broadcasting Company, Ontario.

Bont, Jan de, 2003, Lara Croft Tomb Raider: The Cradle of Life, Paramount Pictures/Mutual Film Company/British Broadcasting Corporation/ Lawrence Gordon Productions/Eidos Interactive/Tele München Fernseh Produktionsgesellschaft/Toho-Towa/October Pictures, Estados Unidos.

Cameron, James, 1984, The Terminator, Hemdale Film/Cinema 84/Euro Film Funding/Pacific Western, Estados Unidos.

__, 1991, Terminator 2: Judgment Day, Carolco Pictures/Pacific Western/Lightstorm Entertainment/Canal+/T2 Productions, Estados Unidos.

Canaan, Christopher, Leslie Greif, Paul Haggis et al. (dirs.), 1993-2001, Walker Texas Ranger, serie de televisión, Columbia Broadcasting System/Columbia TriStar Television/Cannon Television/Amadea Film Productions/Norris Brothers Entertainment, Estados Unidos.

Cosmatos, George P., 1985, Rambo: First Blood Part II, Tri-Star Pictures/Carolco Pictures, Estados Unidos.

Gilligan, Vince, Adam Bernstein, Jim McKay et al. (dirs.), 2008-2013, Breaking Bad, serie de televisión, Sony Pictures Television/Gran Via Productions/American Movie Classics/High Bridge Productions/High Bridge Entertainment, Estados Unidos.

Kotcheff, Ted, 1982, Rambo: First Blood, Orion Pictures/Anabasis N.V./Elcajo Productions/Carolco Pictures, Estados Unidos.

Lin, Justin, 2013, Fast \& Furious 6, Universal Pictures/Relativity Media/Original Film/One Race Films/Etalon Film, Estados Unidos.

Lynch, Paul, Michael Vejar, Allan Eastman, Mario Azzopardi et al. (dirs.), 1994-1995, Robocop, serie de televisión, temporada 1, Robocop Productions Ltd./Rysher Entertainment/Skyvision Entertaiment, Canadá.

MacDonald, Peter, 1988, Rambo III, Carolco Pictures, Estados Unidos.

Padilha, José (dir.), 2007, Tropa de elite, Zazen Produções/Posto 9/Feijão Filmes/The Weinstein Company/Estúdios Mega/Quanta Centro de Produções Cinematográficas/Universal Pictures do Brasil/Costa Films, Río de Janeiro.

Silverstein, Craig, Eagle Egilsson, Kenneth Fink (dirs.), 2010-2013, Nikita, serie de televisión, Sesfonstein Productions/Wonderland Sound and Vision/Warner Bros. Television/Nikita Films, Ontario.

Stallone, Sylvester, 2008, Rambo, Millennium Films/Nu Image Films/Emmett/Furla Films for Equity Pictures Medienfonds, Estados Unidos. Tarantino, Quentin, 2003, Kill Bill vol. 1, Miramax, Estados Unidos. , 2004, Kill Bill vol. 2, Miramax, Estados Unidos.

Trapero, Pablo (dir.), 2002, El bonaerense, Centre National de la Cinématographie/Ministerio de Cultura y Comunicaciones/Ibermedia/ Instituto Nacional de Cine y Artes Audiovisuales/Pablo Trapero Productions/Pol-Ka Producciones/Wood Producciones, Buenos Aires.

West, Simon, 2001, Lara Croft: Tomb Raider, Paramount Pictures/Mutual Film Company/British Broadcasting Corporation/Lawrence Gordon Productions/Marubeni/Eidos Interactive/KFP Produktions GmbH \& Co. KG/Tele München Fernseh Produktionsgesellschaft/TohoTowa, Estados Unidos. 